\title{
Novel Use of Flexible Paediatric Video-Ureteroscope to Confirm Double Lumen Tube Placement as an Alternative to the Conventional Bronchoscope
}

\author{
Gupta Bhavna ${ }^{1}$, Kumar Mohit ${ }^{2 *}$, Talawar Praveen ${ }^{3}$, Ittoop Amanta Lucy ${ }^{4}$ \\ ${ }^{1}$ Assistant Professor, ${ }^{2}$ Senior Resident, ${ }^{3}$ Assistant Professor, ${ }^{4}$ Junior Resident, Anaesthesiology, \\ AIIMS Rishikesh Dehradun, Uttarakhand, India
}

\begin{abstract}
Whilst a double lumen tube (DLT) is the gold standard for one lung ventilation, its double curvatures and increased diameter can make intubation difficult, potentially compounded by a challenging airway. We describe the successful placement of DLT in a difficult airway, and confirmation of the appropriate placement of DLT by using flexible paediatric video-ureteroscope (digital Olympus URF-V2/V2R), without which the purpose of achieving lung isolation was not possible.
\end{abstract}

\section{Introduction}

Selective lung ventilation is required for many thoracic surgeries. Bronchial blockers and DLTs are preferred to perform one-lung ventilation. Achieving one-lung ventilation with a difficult airway for thoracic surgeries requires experienced anaesthesiologists as well as necessary equipment. One lung ventilation with the placement of DLT in a difficult airway in a setting with limited resources is a further challenge for the attending anaesthesiologist. ${ }^{1}$ The position of DLT was confirmed by auscultation and inspection of chest rise in earlier years, which can now be confirmed with the help of fibre optic bronchoscope ${ }^{2}$. The challenge arises when the adult fibre optic bronchoscope is not negotiated via the lumen of the DLT or when a paediatric fibreoptic bronchoscope is not available. We hereby describe the challenges we encountered in achieving one lung ventilation and confirmation of same with the help of a unique deviceflexible paediatric video-ureteroscope.

\section{Case Report}

A 35-year-old male, post-op case of carcinoma alveolus, left side underwent wide local excision

*Correspondence: Kumar Mohit

E mail: drmohitsaini87@gmail.com

https://orcid.org/0000-0003-1291-4830

Received: 22/07/2020

Accepted: 02/09/2020

DOI: http:/doi.org/10.4038/slja.v29i1.8642

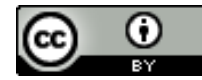

of tumour, hemi-mandibulectomy, modified radical neck dissection, and reconstruction with pectoralis-major myo-cutaneous-flap. $\mathrm{He}$ was scheduled for thoracoscopic duct ligation due to persistent chyle leak and recurrence of the tumour on the left side of the neck. He was a chronic tobacco chewer and smoker. Airway examination suggested a difficult airway, reduced mouth opening, modified mallampati classification III, restricted tongue protrusion, and restricted neck movements due to the previous flap.

In the operating theatre, all standard monitors were attached. Pre oxygenation was achieved via nasal cannula. After induction and confirmation of ability to mask ventilate, succinylcholine was given, followed by direct laryngoscopy using McCoy laryngoscope, Cormack Lehane (CL) grade 3 improved to CL grade II-B on manoeuvring. The trachea was intubated with left-sided 37F DLT in a single attempt. Correct placement was confirmed by auscultation. Objective confirmation was made with flexible paediatric video-ureteroscope, sized $2.8 \mathrm{~mm}$, taken on request from paediatric surgeons.

In the modern era, DLT and bronchial blocker have made lung separation easy and safe but achieving one-lung ventilation with placement and confirmation of DLT in difficult airway with limited resources is a great challenge for the attending anaesthesiologist. Because of anticipated difficult intubation and difficult mask ventilation, we should have gone with awake fibre optic bronchoscope (FOB) guided insertion of DLT, but the largest available DLT size 41 could not be negotiated over available 
size adult FOB, and size 35 and 37 occupied the entire short length of paediatric ambuscope available to us. Our second plan of airway management was awake FOB guided single lumen ETT placement but airway exchange catheter available to us could not be negotiated via size 37 DLT. Intubation with DLT is more challenging than a single lumen tube (SLT) in an anticipated difficult airway. DLT has a larger outer diameter, longer and is less malleable compared to the SLT ${ }^{[3]}$. Pre warming of DLT helps in making a hockey stick configuration at the distal end of the tube. The larger size and absence of a bevel at the tip may further obscure view during laryngoscopy. The use of the McCoy laryngoscope blade drastically improved our glottic view. Appropriate sized single lumen tube and laryngeal mask airway were kept ready in case of failed intubation.

\section{Discussion}

Incorrect placement of DLT in thoracic surgeries can cause difficulties to manage a patient during an intraoperative period as well as in postoperative period which may affect the surgical outcome ${ }^{4}$. Uwe Klein et al concluded that fiberoptic bronchoscopy reduced the incidence of mal-positioning of DLT as well as have a therapeutic role to remove secretions and blood clots. $^{5}$

We would like to emphasize the importance of using flexible paediatric video-ureteroscope URF-V2/V2R, for confirming the appropriate placement of DLT, without which the purpose of achieving lung isolation was not possible. The flexible paediatric video-ureteroscope is longer as compared to the FOB, it passed via the entire length of DLT and provided a better field of vision. It provides an angulation of 275 degrees up and down as compared to fibreoptic bronchoscope which provides 160 degrees up and 90 degrees down angulation. The flexible paediatric vide- ureteroscope (Olympus URFV2/V2R) sized $2.8 \mathrm{~mm}$ features a micro mini CCD (charge-couple device) that enables the outer diameter to be significantly smaller than the previous generation flexible video ureteroscope, hence it could be negotiated via DLT. (Fig.1)

\section{Conclusion}

The anticipation of a difficult airway, appropriate planning, and preparedness helped

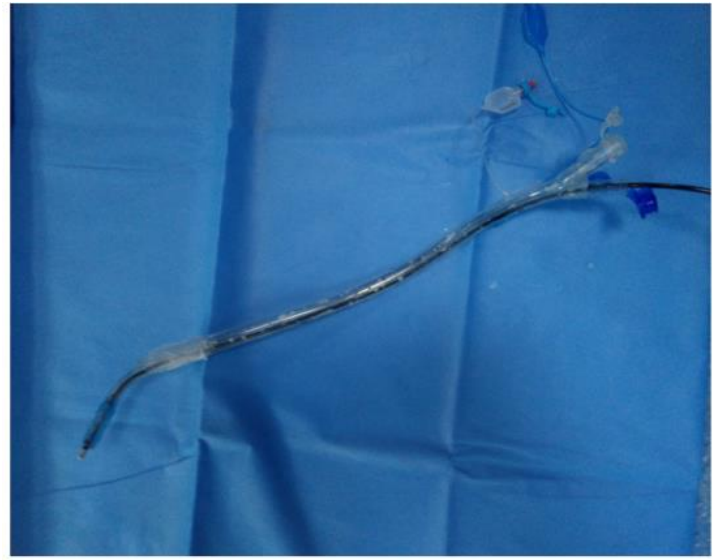

\section{Figure 1}

Insertion of flexible paediatric videoureteroscope inside Size 32 Double lumen tube

us to manage to secure and confirm the accurate placement of DLT in a difficult airway despite limited resources. The flexible paediatric videoureteroscope can be used for confirmation of placement of all available adult sizes doublelumen tubes and its future modifications as a modified device (combo paediatric uretrobronchoscope) with the attachment of suction channel and oxygen port can pave a way to its use in primary airway management of a difficult airway.

\section{References}

1. Brodsky JB. Lung separation and difficult airway. British journal of anaesthesia. 2009 Dec 1; 103 (suppl_1): i66-75.

https://doi.org/10.1093/bja/aep262

PMID: 20007992

2. Cohen E. Double-lumen tube position should be confirmed by fibre-optic bronchoscopy. Current Opinion in Anaesthesiology. 2004 Feb 1; 17 (1): 1-6.

https://doi.org/10.1097/00001503-200402000$\underline{00002}$

PMID: 17021522

3. Gupta B, Gupta L. Significance of the outer diameter of an endotracheal tube: a lesser-known parameter. Korean J Anaesthesiol 2019; 72: 72-3. https://doi.org/10.4097/kja.d.18.00056 PMID: 29843505

4. Gupta B, Khan A, Ghosh D. Lung isolation in an elderly, post radiation fibrosis of a difficult airway-paediatric double lumen tube and ureteroscope as rescue device. Saudi J Anaesth 2020; 14: 281-3.

https://doi.org/10.4103/sja.sja_48_20 PMID: 32317905

5. Klein U, Karzai W, Bloos F, Wohlfarth M, Gottschall R, Fritz H, Gugel M, Seifert A. Role of 
Mohit et al. Sri Lankan Journal of Anaesthesiology: 29(1): 52-54 (2021)

fiber-optic bronchoscopy in conjunction with the use of double-lumen tubes for thoracic anaesthesia a prospective study. Anaesthesiology:

The Journal of the American Society of Anaesthesiologists. 1998 Feb 1; 88 (2): 346-50. https://doi.org/10.1097/00000542-199802000$\underline{00012}$ 